\title{
EDITORIAL
}

\section{The Berlin definition met our needs: not sure}

\author{
Jean-Louis Vincent ${ }^{*}$
}

๑ 2016 Springer-Verlag Berlin Heidelberg and ESICM

I was fortunate to be one of the participants involved in elaborating the new criteria for the acute respiratory distress syndrome (ARDS) in Berlin in 2012 [1]. I appreciated the discussions during this process and support the outcome. At the same time, I respectfully wonder whether this intellectual performance really helps our patients. Developing new definitions may appear to bring some uniformity to the patient populations included in clinical trials, but it does not eliminate the underlying heterogeneity; it may, therefore, actually contribute to generate additional negative trials. So are these new ARDS definitions really a major advance?

As soon as new criteria are developed, studies are designed to investigate the "new" epidemiology associated with the somewhat modified syndrome. The recent Lung Safe study is a good example of this phenomenon [2]. In this large observational study of almost 30,000 patients, $10 \%$ met the Berlin ARDS criteria: $30 \%$ of these patients had mild ARDS, $47 \%$ moderate, and $23 \%$ severe. The hospital mortality rates were 35,40 , and $46 \%$ in mild, moderate, and severe forms, respectively. But do these data really matter? Are they of interest? And to whom? To the doctor or to the patient? The essential question from the patient's perspective is, "will these new definitions really help me? And if you decide I have ARDS, how will it affect how you treat me?" [3].

We know that the risk of iatrogenic ventilator-induced lung injury (VILI) is high in ARDS, so that a protective ventilation strategy must be used, including giving small tidal volumes. However, we have also learned that this strategy must also be applied in other patients receiving

\footnotetext{
*Correspondence: jlvincen@ulb.ac.be

Department of Intensive Care, Erasme Hospital, Université libre de

Bruxelles, Route de Lennik 808, 1070 Brussels, Belgium
}

Contrasting viewpoints can be found at doi:10.1007/s00134-016-4242-6 and doi:10.1007/s00134-016-4286-7. mechanical ventilation, even those who are ventilated for the limited period of a surgical intervention [4]. Likewise, we need to monitor airway pressures in all mechanically ventilated patients, not just those with ARDS, and must try to apply at least some positive end-expiratory pressure (PEEP) in all patients with marked hypoxemia. And the use of high frequency ventilation in ARDS may be more harmful than beneficial [5]. Hence, the fact that a patient is identified as having ARDS rather than another form of severe acute respiratory failure does not really influence the ventilator settings. Profound sedation, even with muscle relaxants, may be needed initially to minimize VILI but this still needs to be confirmed by a large ongoing trial (ClinicalTrials.gov Identifier: NCT02509078); in any case, once again, this approach may be necessary in all forms of severe respiratory failure. Prone positioning in severe cases may improve outcomes, but it is not always feasible practically. In the Lung Safe study [2], prone positioning was applied in only $16 \%$ of cases of severe ARDS, but in how many of the other $84 \%$ of patients was it considered as impractical, because of the presence of drains, a distended abdomen, or simply an inexperienced team?

Importantly, despite many attempts and many negative clinical trials, the place of corticosteroids is still undefined and no beneficial ARDS-specific pharmacological intervention has been developed [6]. The main reason for this lack of success is the heterogeneity of the syndrome, even at the pathology level. Autopsy $[7,8]$ and biopsy [9, 10] studies have revealed that only about $50 \%$ of ARDS patients have the typical diffuse alveolar damage (DAD) pattern. The presence of DAD was associated with more severe disease and a greater likelihood of death associated with hypoxemia [8].

We have such a heterogeneous patient population in our ICUs (Fig. 1) that we try to create some uniformity by grouping them together in one way or another. However,

\section{Springer}




81 Y/O 71 Y/O 57 Y/O 27 Y/O
Heart failure Peritonitis Pancreatitis Polytrauma
Renal failure $\begin{gathered}67 / 0 \\ \text { SAH }\end{gathered}$
Devere CAP
Senal failureBrain injury Pneumonia
Diabetes

identifying ARDS, with or without modified criteria, provides a false sense of homogeneity. We may think we have a diagnosis, when in fact we may only be partway there. The same false sense of security can occur with a diagnosis of sepsis [11].

The label 'ARDS' could be a marker of severity, but so could severe hypoxemia. Exploring whether or not a patient meets specific criteria may not change that patient's outcome. Using the Berlin criteria, or indeed any other set of criteria, may lead to milder forms of ARDS being underdiagnosed [2], but is this a problem when there is no specific therapeutic intervention available anyway?

The real problem is that once a patient meets the Berlin criteria and is labeled as having ARDS, the clinician may consider that a "diagnosis" has been made and there is therefore no need to look any further, so that the important search for an underlying etiology may be forgotten or at least deferred. Yet a diagnosis of ARDS is actually not a diagnosis. A favorable course of ARDS is usually associated with resolution of the underlying causative condition, and failing to identify the cause and control it may result in multiple organ failure and death.

So, do the new criteria for ARDS represent real scientific progress? Should we continue to discuss and debate the details of these criteria? The answer has to be that I am not sure. New definitions certainly encourage new epidemiological studies, which provide useful additional information regarding the burden of disease, risk factors, and prognostic features, but new criteria do not necessarily help in the development of new therapeutic strategies. We should never forget that syndromes are not diseases, and survival from these conditions often depends as much, if not more, on the identification of an underlying cause that must be controlled than on any form of specific organ support. Development and use of pharmacological strategies in the future will be guided by specific biomarkers more than by re(de)fined clinical criteria [12].

Compliance with ethical standards

Conflicts of interest

The author declares he has no conflicts of interest related to this manuscript.

Received: 9 March 2016 Accepted: 9 March 2016

Published online: 23 March 2016

\section{References}

1. Ferguson ND, Fan E, Camporota L, Antonelli M, Anzueto A, Beale R, Brochard L, Brower R, Esteban A, Gattinoni L, Rhodes A, Slutsky AS, Vincent $J$, Rubenfeld GD, Thompson BT, Ranieri VM (2012) The Berlin definition of ARDS: an expanded rationale, justification, and supplementary material. Intensive Care Med 38:1573-1582

2. Bellani G, Laffey JG, Pham T, Fan E, Brochard L, Esteban A, Gattinoni L, van HF, Larsson A, McAuley DF, Ranieri M, Rubenfeld G, Thompson BT, Wrigge H, Slutsky AS, Pesenti A (2016) Epidemiology, patterns of care, and mortality for patients with acute respiratory distress syndrome in intensive care units in 50 countries. JAMA 315:788-800

3. Vincent JL, Santacruz C (2016) Do we need ARDS? Intensive Care Med 42:282-283

4. Sutherasan $Y$, Vargas M, Pelosi P (2014) Protective mechanical ventilation in the non-injured lung: review and meta-analysis. Crit Care 18:211

5. Ferguson ND, Cook DJ, Guyatt GH, Mehta S, Hand L, Austin P, Zhou Q, Matte A, Walter SD, Lamontagne F, Granton JT, Arabi YM, Arroliga AC, Stewart TE, Slutsky AS, Meade MO (2013) High-frequency oscillation in early acute respiratory distress syndrome. N Engl J Med 368:795-805

6. Vincent JL, Santacruz C (2015) Traitement de I'ARDS: Ce qui est basé sur l'évidence. Communications Scientifiques 2015. MAPAR Editions, Le Kremlin Bicêtre, pp 177-180

7. de Hemptinne Q, Remmelink M, Brimioulle S, Salmon I, Vincent JL (2009) ARDS: a clinicopathological confrontation. Chest 135:944-949

8. Lorente JA, Cardinal-Fernandez P, Munoz D, Frutos-Vivar F, Thille AW, Jaramillo C, Ballen-Barragan A, Rodriguez JM, Penuelas O, Ortiz G, Blanco J, Pinheiro BV, Nin N, Del Carmen MM, Esteban A, Thompson TB (2015) Acute respiratory distress syndrome in patients with and without diffuse alveolar damage: an autopsy study. Intensive Care Med 41:1921-1930. doi:10.1007/s00134-015-4046-0

9. Kao KC, Hu HC, Chang CH, Hung CY, Chiu LC, Li SH, Lin SW, Chuang LP, Wang CW, Li LF, Chen NH, Yang CT, Huang CC, Tsai YH (2015) Diffuse alveolar damage associated mortality in selected acute respiratory distress syndrome patients with open lung biopsy. Crit Care 19:228

10. Guerin C, Bayle F, Leray V, Debord S, Stoian A, Yonis H, Roudaut JB, Bourdin G, Devouassoux-Shisheboran M, Bucher E, Ayzac L, Lantuejoul S, Philipponnet C, Kemeny JL, Souweine B, Richard JC (2015) Open lung biopsy in nonresolving ARDS frequently identifies diffuse alveolar damage regardless of the severity stage and may have implications for patient management. Intensive Care Med 41:222-230. doi:10.1007/s00134-014-3583-2

11. Vincent JL, Mira JP, Antonelli M (2016) Sepsis: older and newer concepts. Lancet Respir Med 4:237-240

12. Vincent $J$ (2016) Individual gene expression and personalised medicine in sepsis. Lancet Respir Med. doi:10.1016/S2213-2600(16)00068-0 